\title{
Evaluation of Garden State Parkway Alternate Bus Routing Field Operational Test
}

\author{
Kaan Ozbay, Tilanka Karunaratne, and Trefor Williams \\ Department of Civil and Environmental Engineering, Rutgers University \\ Diogenes Feldhaus and Mohsen Jafari \\ Department of Industrial Engineering, Rutgers University
}

\begin{abstract}
$\overline{\text { Abstract }}$
This study evaluates the effectiveness of the New Jersey Garden State Parkway (GSP) Alternate Bus Routing (ABR) system, an Advanced Public Transportation System (APTS). The GSP ABR Field Operational Test (FOT), which was conducted on a small portion of the parkway, was mainly concerned with real-time routing of New Jersey Transit (NJT) buses traveling the GSP to a parallel alternate route to avoid congestion on the parkway.

One of the most important features of this FOT is the use of NJT buses as probe vehicles that provide real-time travel-time information to the bus routing algorithm. The use of probe vehicles for network surveillance increases the attractiveness of similar systems that can be deployed over larger networks where infrastructure-based surveillance can be prohibitively expensive. The functional evaluation of GSP ABR includes the collection and analysis of data from various sources including traffic sensors, probe vehicles, and surveys conducted among transit bus operators and system users.
\end{abstract}

During the official testing period in 1997, the GSP ABR system produced accurate diversion messages, which proved the reliability of the system. However, the rela- 
tively short length of the alternate route, U.S. Route 9, and similar traffic patterns observed on both routes did not give the evaluation team the opportunity to observe scenarios where statistically significant travel-time improvements exist. This result prevented the evaluation team from reaching conclusive recommendations in terms of the effectiveness of this FOT. However, the survey results show that both transit bus operators and ABR system operators believe the system can be very beneficial if implemented in a different network.

From a policy point of view, the general conclusions of the functional tests presented along with a list of lessons learned can be used in the effective design of future FOTs in the area of APTS.

\section{Introduction}

One of the most efficient ways to understand and assess the effectiveness of Intelligent Transportation Systems (ITS) in improving the existing transportation system is through the implementation of FOTs. FOTs are projects aimed at deploying promising ITS technologies in relatively small-scale networks. Evaluation of these FOTs is an integral part of the overall tests, because the major goal for the limited deployment of ITS technologies is to assess the effectiveness of the deployed ITS technology and draw general conclusions that can be used to ensure success of future large-scale ITS deployment projects. Currently, most ITS FOTs deal with passenger vehicles and related infrastructure. However, public transportation can be equally impacted by the use of advanced technologies recently introduced in the context of ITS. To better understand possible effects of advanced ITS technologies on public transit, real-world field implementation of these technologies and subsequent evaluation of their effectiveness is needed.

The GSP ABR FOT project is concerned with real-time routing of NJT buses to avoid congested highway stretches along the test corridor shown in Figure 1. This is similar to the real-time traffic diversion concept implemented by incident management crews to reroute traffic around the closed highway link as a result of a traffic accident (Ozbay and Kachroo 1999). In this project, however, the diversion recommendation is limited to participating NJT buses; the other vehicles are not given any diversion messages. Based on the diversion 


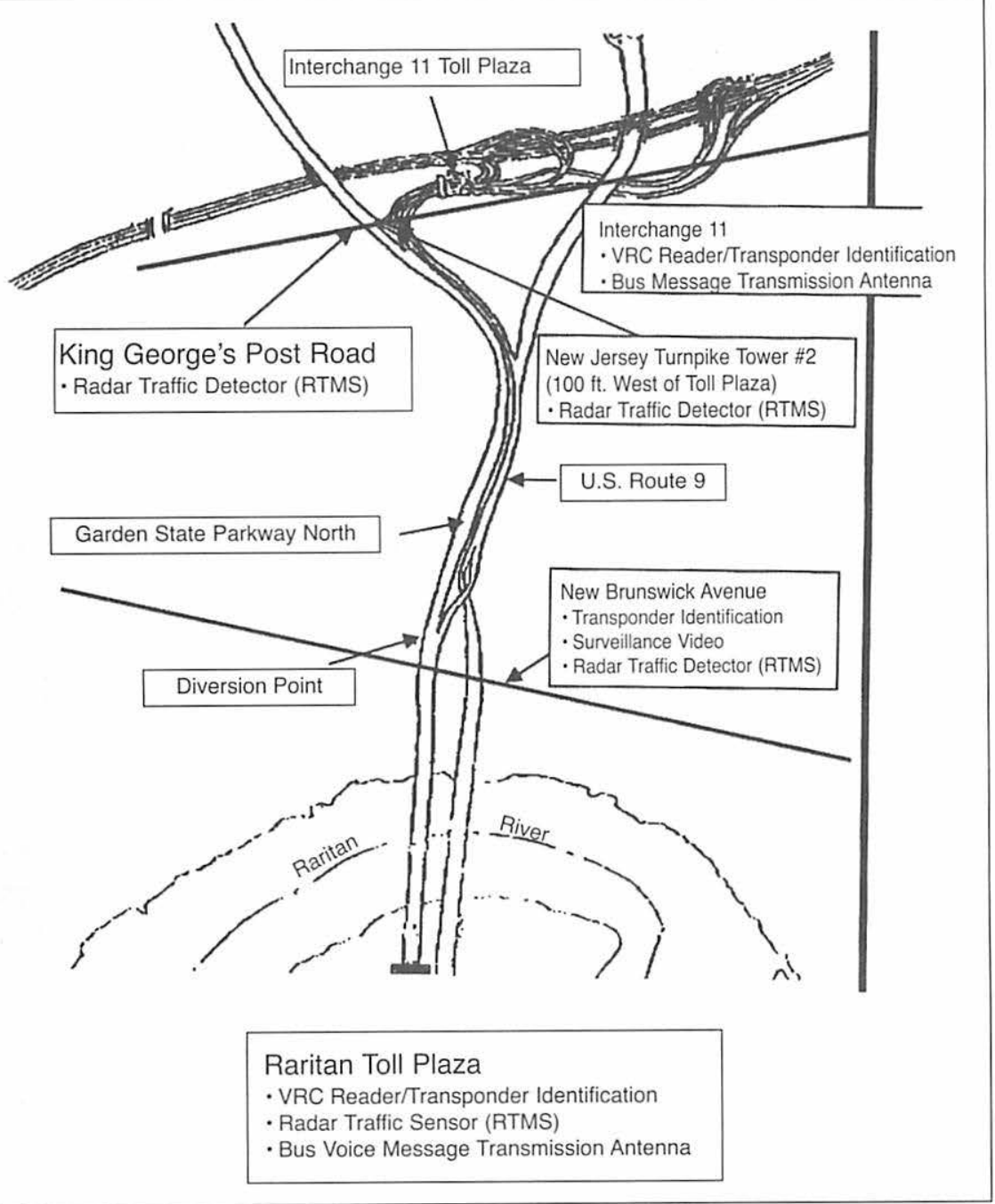

Source: Based on U.S. Department of Transportation (DOT) Federal Highway Administration (FHWA), 1966.

Figure 1. GSP ABR network

recommendation generated by the GSP ABR system, NJT buses are routed in real time to an alternate route, U.S. 9.

This article has three main objectives:

1) to describe the FOT and the plan developed specifically to evaluate the deployment of this APTs; 
2)to present the evaluation results of this unique advanced public transit FOT performed in one of the most heavily congested areas of the United States; and

3)to present a list of general conclusions and lessons learned that can be used as a future guide for the implementation of similar ITS projects in the context of public transit systems.

\section{Project Overview}

The ABR project on the GSP is an operational field test designed to improve the efficiency of NJT buses traveling the parkway and to reduce the commuting time of bus passengers. The system is expected to accomplish these goals by transmitting real-time routing diversion messages directly to the NJT buses heading north toward New York City at the entrance of the project location at the Raritan Toll Plaza.

Figure 1 represents the layout of the ABR system network. The route guidance system obtains real-time traffic information from road sensors and probe buses and makes a decision regarding whether diversion from the GSP to the alternate route is warranted. If the answer is positive, the diversion message is broadcast to incoming NJT buses through annunciators installed in the buses.

The project was planned as a two-phase effort. During the first phase, 50 NJT buses equipped with Automatic Vehicle Identification (AVI) transponders and audio annunciators acted as probe vehicles. Based on the results of the Phase 1 evaluation, a decision was made regarding implementation of Phase 2, which required the instrumentation of the remaining $350 \mathrm{NJT}$ buses. Thus, the results of Phase 1's evaluation played an important role in determining if it was feasible to continue with the implementation of Phase 2.

The GSP ABR project, which can be identified as an ITS FOT, was designed to satisfy six national goals for ITS projects identified by the FHWA (U.S. DOT 1996):

1) improve the safety of the nation's surface transportation system;

2) increase the operational efficiency and capacity of the surface transportation system;

3) reduce environmental costs associated with traffic congestion; 
4)enhance present and future productivity;

5)enhance the personal mobility and convenience and comfort of the surface transportation system; and

6)create an environment in which the development and deployment of ITS can flourish.

Based on these goals, the evaluation team identified three major goals for this project:

1) enhance system performance by reducing NJT bus travel time during the morning rush hour by transmitting real-time diversion information directly to participating NJT buses;

2)ensure GSP ABR system reliability in terms of routing decisions that depend, in turn, on the reliability of traffic sensors, proven vehicle data, and the routing algorithm; and

3)ensure user acceptance by proving to the users (i.e., limited-case transit operators) that the GSPABR will enhance the mobility of the existing system.

Table 1 shows the relationship of the goals of the ABR project to the national ITS goals.

\section{The GSP ABR Demonstration Project}

This FOT involved three transportation agencies: NJT, New Jersey Highway Authority, and TRANSCOM, which is a partnership of a number of agencies in New Jersey and New York.

\begin{tabular}{|c|c|c|c|c|c|c|}
\hline \multicolumn{7}{|c|}{$\begin{array}{l}\text { Table } 1 \\
\text { Relationship between ITS Goals and ABR Goals }\end{array}$} \\
\hline ITS Goals & $\begin{array}{l}\text { Improve } \\
\text { Safety }\end{array}$ & $\begin{array}{c}\text { Increase } \\
\text { Efficiency }\end{array}$ & $\begin{array}{c}\text { Reduce } \\
\text { Environmental } \\
\text { Costs }\end{array}$ & $\begin{array}{c}\text { Enhance } \\
\text { Productivity }\end{array}$ & $\begin{array}{l}\text { Enhance } \\
\text { Personal } \\
\text { Mobility }\end{array}$ & $\begin{array}{c}\text { Promote } \\
\text { ITS }\end{array}$ \\
\hline $\begin{array}{c}\text { System } \\
\text { Performance }\end{array}$ & $\sqrt{ }$ & $\sqrt{ }$ & $\sqrt{ }$ & $\sqrt{ }$ & $\sqrt{ }$ & $\sqrt{ }$ \\
\hline $\begin{array}{c}\text { System } \\
\text { Reliability }\end{array}$ & $\sqrt{ }$ & & & & & $\checkmark$ \\
\hline User Acceptance & & $\sqrt{ }$ & & $\sqrt{ }$ & $\sqrt{ }$ & $\checkmark$ \\
\hline
\end{tabular}


This ABR FOT was located between GSP milepost 125.4 and New Jersey Turnpike interchange-11 (NJT-11) shown in Figure 1. The main goal of the ABR project was the development of a bus routing system that provides realtime alternate routing information to NJT buses traveling northbound on the GSP. In the absence of diversion messages, all the NJT buses used the GSP, the primary route according to the ABR system. However, in the event of excessive congestion on the GSP, NJT buses were diverted to the secondary route. Table 2 summarizes the functional capabilities of the GSP ABR system.

The GSP ABR system physical architecture (shown in Figure 2) was comprised of these components installed at locations in the test network shown in Figure 1:

- Remote Traffic Microwave Sensors (RTMS),

- VRC transponder/reader,

- audio annunciators, and

- surveillance camera.

\section{Functional Analysis of the System}

Functional analysis measures the performance of the individual system components as well as the performance of the complete integrated system. The evaluation tests developed in this FOT are briefly explained in Table 3. Table 4 shows the relationship between the evaluation tests developed and the major goals of this FOT.

\section{Data Sources}

Data for the ABR project was obtained from two main sources, Rutgers University instrumented vehicle and ABR system traffic sensors.

\section{Rutgers University Instrumented Vehicle Data}

Two vehicles instrumented with AVI tags were used by Rutgers University to collect independent travel-time data along the study site on the GSP and U.S. 9. Experimental configuration of a Rutgers instrumented vehicle and its relationship to the rest of the GSP ABR system is shown in Figure 3. The instrumented vehicle had all the equipment that the NJT buses had. This configuration was needed to ensure proper testing of the hardware functions of the system. 
Table 2

\section{Functional Capabilities of Data Processing Centers of the ABR System}

Raritan Toll Plaza-Mile Post 125.4

- RTMS sensor-GSP data monitored

- VRC reader

- Bus message transmission antenna

- Radio communications between TOC and equipment at Raritan Toll Plaza

- Inner roadway has 3 lanes; outer roadway has 4 lanes

- Equipment is placed and installed on the variable message sign

New Brunswick Avenue-Mile Post 128.4

-Surveillance camera

.RTMS sensor-U.S. 9 and GSP data monitored

.VRC transponder

-Equipment is mounted on southern face of the New Brunswick Avenue overpass

- Radar and VCR transponder cover all 5 inner lanes of GSP and all 4 outer lanes of U.S. 9

-Radio communications with TOC and New Brunswick Avenue overpass

King George's Post Road-Mile Post 129.1

-RTMS radar traffic data-GSP and U.S. 9 data monitored

- Radar is mounted at the overpass abutment to give complementary traffic information

-Detector covers both ramps from U.S. 9 to New Jersey Turmpike and the outer lanes of GSP that feed the

- ramp to the turnpike

-Ramps from U.S. 9-3 lanes

.GSP north lanes- 5 lanes

New Jersey Turnpike Tower \# 2-100 ft. West of the Toll Plaza

-RTMS radar traffic detector is mounted at the tower-monitors GSP and U.S. 9

.GSP and U.S. 9 merges at this point

New Jersey Turnpike Sign Structure-2500 ft. East of the Toll Plaza

-VRC reader

- Bus message transmission antenna

- Sign structure at the northbound New Jersey Turnpike entrance ramp

-VCR beacon mounted over the signAll 3 lanes of the ramp are covered by the VCR transponder

New Jersey Turnpike Headquarters-New Brunswick

- Send bus messages-at exit 11 only

- Summary of traffic data and reports

- Ability to view surveillance video from the camera placed at New Brunswick Avenue

New Jersey Transit Operations-Maplewood

- Bus message override

- Summary of traffic data and reports

- Ability to view surveillance video from the camera placed at New Brunswick Avenue

TRANSCOM Jersey City

- Ability to view surveillance video from the camera placed at New Brunswick Avenue

New Jersey Transit Operations-Maplewood

- Connect all above-cited sites

- Recording of voice messages

- Display traffic data

- Generate statistical reports

- Analyze real-time traffic data

- Determine optimum advisory message

- Ability to override messages

- Ability to control camera at New Brunswick A venue

Source: Based on information provided by Hughes Electronics, 1995.

Vol. 3, No. 4, 2001 


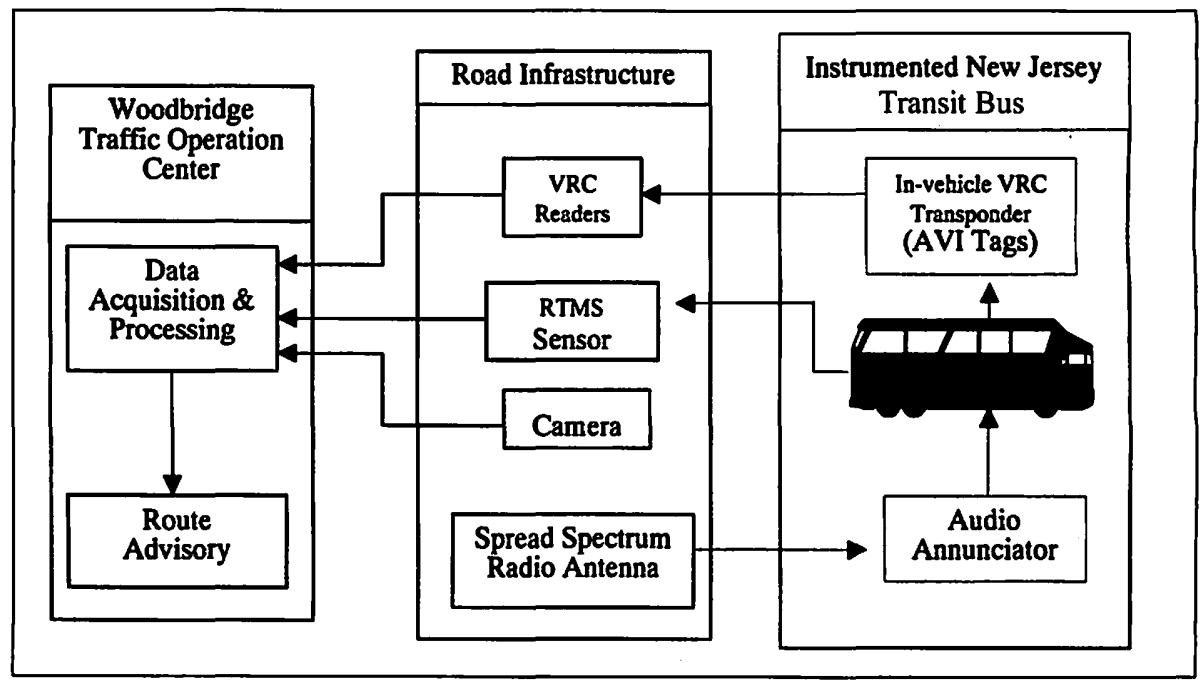

Figure 2. System architecture of ABR project

Data were obtained during the peak rush-hour periods (6:30-9:00 A.M.) when a diversion condition was most likely to occur. The instrumented vehicles were used to perform synchronized parallel runs to determine travel-time differences between the primary (GSP) and alternate route (U.S. 9). The two test vehicles entered the Raritan Toll Plaza on the GSP simultaneously, then separated at the diversion point, and met at the end of each run after NJT-11 at the New Jersey Turnpike. Both drivers completed travel logs after each run, and included the test time (synchronized with the ABR system) and length of travel times for each predetermined station point along the route. Travel-time data were compared with ABR system output to evaluate system travel-time data accuracy.

The transponders in the test vehicles were turned on once a day for a complete run for (1) testing the messaging function of the system and (2) testing the accuracy of the "tagged" travel times obtained by the system. Transponders were not turned on during all the test runs to avoid the risk of introducing bias to the traveltime estimation of the ABR system algorithm due to the additional probe data.

\section{ABR System Data}

The operator at the traffic operation center at the New Jersey Highway Authority provided the following information daily for the 6:00-9:00 A.M. time period: 


\section{Table 3}

\section{Evaluation Test Numbers, Names, Symbols, and Descriptions}

\begin{tabular}{c|c|c}
\hline $\begin{array}{c}\text { Test } \\
\text { Number }\end{array}$ & Test Name & Test Description \\
\hline Functional & Testing
\end{tabular}

\begin{tabular}{|l|l|l|}
\hline FPT-01 & Bus Routing & $\begin{array}{l}\text { Verifies that the routing system is functioning properly under a } \\
\text { range of conditions. }\end{array}$ \\
\hline FPT-02 & Audio Messaging & $\begin{array}{l}\text { Verifies that the audio messages received by the bus drivers } \\
\text { are comprehensible. }\end{array}$ \\
\hline FPT-04 & $\begin{array}{l}\text { Traffic-Volume Data } \\
\text { Accuracy }\end{array}$ & $\begin{array}{l}\text { Verifies that the traffic volume collected by the system is } \\
\text { accurate to a given degree of accuracy. }\end{array}$ \\
\hline FPT-05 & $\begin{array}{l}\text { Travel-Time Data } \\
\text { Accuracy }\end{array}$ & $\begin{array}{l}\text { Verifies that the travel-time data collected by the automatic } \\
\text { system is accurate to a given degree of accuracy. }\end{array}$ \\
\hline System-Wide Performance Testing \\
\hline SW-01 & $\begin{array}{l}\text { Bus Travel-Time } \\
\text { Reduction }\end{array}$ & $\begin{array}{l}\text { Will analyze and determine the reduction (if any) in bus travel } \\
\text { time due to the automatic traffic management system. If } \\
\text { possible, this test should take into account a wide range of } \\
\text { possible scenarios reflecting normal traffic conditions, high- } \\
\text { peak (e.g., during holidays) conditions. }\end{array}$ \\
\hline SW-03 & $\begin{array}{l}\text { Consumer } \\
\text { Satisfaction }\end{array}$ & $\begin{array}{l}\text { Will analyze and determine consumer satisfaction due to better } \\
\text { bus routing and reduced travel time. }\end{array}$ \\
\hline
\end{tabular}

\begin{tabular}{|c|c|c|}
\hline \multicolumn{3}{|c|}{$\begin{array}{c}\text { Table } 4 \\
\text { Relationship between Evaluation Tests and ABR Goals }\end{array}$} \\
\hline Goal I & Evaluate System Performance & Tesis \\
\hline 1. & Assess reduction in bus travel time due to routing change. & SW-01 \\
\hline 2. & Assess algorithm capability of selecting the correct route. & SW-01 \\
\hline Goal 2 & Evaluate System Reliability & \\
\hline 3. & Assess traffic-volume data collected by the system. & FPT-04 \\
\hline 4. & Assess travel-time data collected by the system. & FPT-05 \\
\hline Goal 3 & Evaluate User Acceptance & \\
\hline 5. & Assess quality of the audio messages. & FPT-02 \\
\hline 6. & Assess acceptance of the routing information by the users. & SW-03 \\
\hline 7. & Assess the best audio message to transmit. & FPT-02 \\
\hline
\end{tabular}




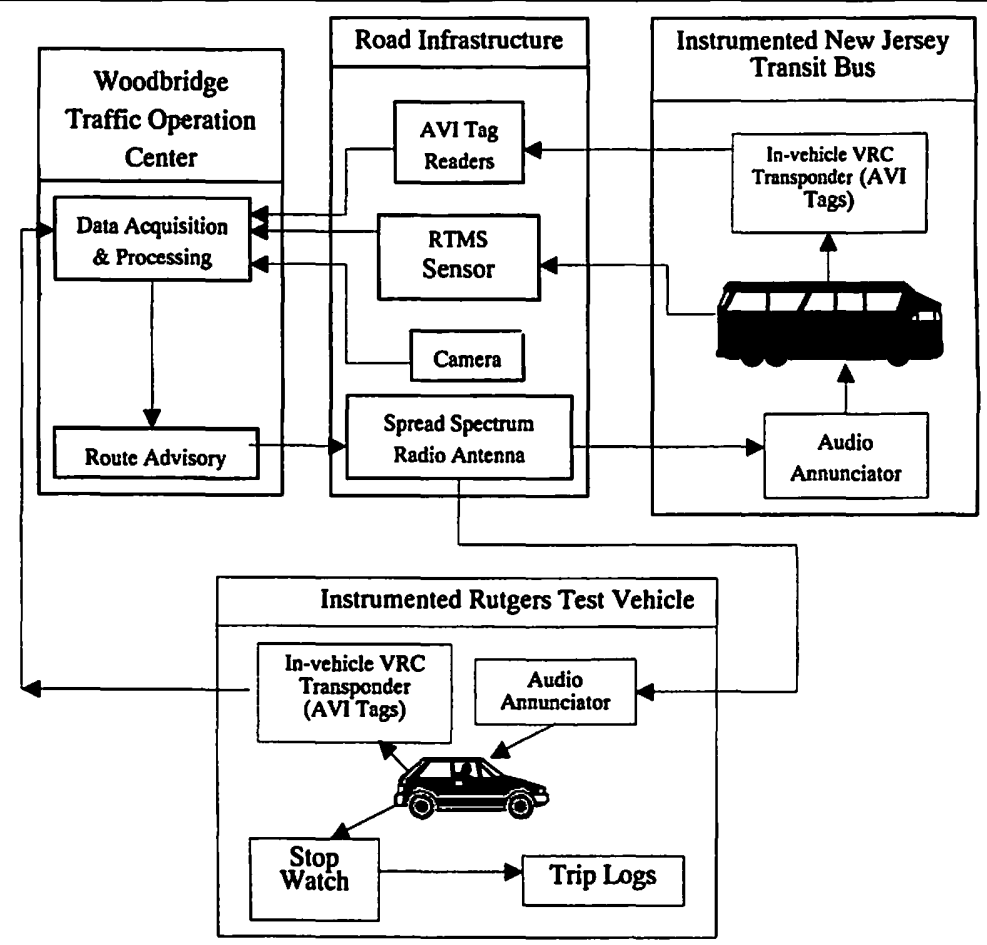

Figure 3. Experimental configuration of instrumented Rutgers test vehicle in the overall context of the GSP bus routing project

- Detector Data. Detector data included the RTMS output for average speed, occupancy, and volume data for each location aggregated over each 30 -second interval.

- Tag Data. AVI tag data provided travel-time information of the NJT buses. These data contained current time, location, bus identity number, route choice, total trip time for each bus, and the current routing message generated by the ABR system.

- System Log Data. Log data consisted of four-minute summaries of the ABR system output. The data included estimated travel times for GSP and U.S. 9; station delays; and five-minute aggregated volume, occupancy, and speed data.

- Video Output. Traffic conditions at New Brunswick Avenue were videotaped from 6:30-9:00 A.M. daily. Apart from enabling visual access to the system from the traffic operations center, these video images were used for traffic volume data accuracy testing. 


\section{Data Collection and Analysis}

The following sections describe the data collection and analysis methods used in this study.

\section{Evaluation of Operation of RTMS Traffic Sensors (FTP-04-Traffic-Volume Data Test)}

A summary of the sample traffic volume data test, which evaluated the accuracy of radar sensors, is shown in Table 5. RTMS have been independently evaluated by the manufacturer as part of other FOTs. However, the evaluation team and participating agencies decided to test the accuracy of the traffic detectors under the existing operating conditions. This test was designed to identify any problems specific to this network and traffic conditions. Thus, the evaluation team used volume counts as the testing criteria because of the relative ease of collecting dependable ground truth volume data. Traffic volume counts were performed at New Brunswick Avenue using video camera images obtained from the traffic operation center. Specifying an alpha value of 5 percent, the true mean, with a confidence of 95 percent, was placed in the following interval of $[0,15.4691]$. Since the confidence interval does cover zero, values do not supply enough evidence to affirm that the Rutgers volume counts versus the system volume counts had different means. According to the collected data, the ABR system had a smaller average volume value than the real average volume value, assuming the Rutgers counts represented the real val-

\begin{tabular}{|c|c|}
\hline \multicolumn{2}{|c|}{$\begin{array}{c}\text { Table } 5 \\
\text { Summary of Sample Volume Count Data } \\
\text { Volume Counting Differences between Rutgers and ABR System }\end{array}$} \\
\hline Date of Volume Data Collection (from 6:50 A.M.-8:20 A.M.) & November 25, 1997 \\
\hline $\begin{array}{l}\text { Average of difference of volume counts: } \\
\text { Volume(Rutgers)-Volume (System) }\end{array}$ & 3.55 \\
\hline $\begin{array}{l}\text { Maximum value of difference of volume counts: } \\
\text { Volume(Rutgers)-Volume (System) }\end{array}$ & 20 \\
\hline $\begin{array}{l}\text { Minimum value of difference of volume counts: } \\
\text { Volume(Rutgers) - Volume (System) }\end{array}$ & -15 \\
\hline Total Volume (Rutgers) & 5653 \\
\hline Total Volume (System) & 5024 \\
\hline $\begin{array}{l}\text { Standard deviation of difference of volume counts: } \\
\text { Volume(Rutgers)-Volume(System) }\end{array}$ & 6.05 \\
\hline Number of observation points & 177 \\
\hline \% Total Difference & $11.12 \%$ \\
\hline
\end{tabular}


ues. The real volume was found to be, on average, 11.1266 percent larger than the volume counts supplied by the ABR system. A detector calibration procedure helped to reduce the difference between the real and system volume counts. Also the radar manual stated that errors up to \pm 5 percent are acceptable for the RTMS counts. This test concluded that both the system and the evaluation team's volume counts did not have a statistically significant difference of means based on the results of the t-test and thus the data collected by RTMS were considered statistically accurate.

\section{Evaluation of the Integrated ABR System's Accuracy (FPT-05-Travel-Time Data Accuracy Test, FTP-01-Bus Routing Test)}

The evaluation of the integrated ABR system's accuracy was performed effectively by analyzing the impact of the integrated system's main output, namely, "the routing decisions." If the routing decisions are appropriate for most of the traffic patterns experienced in the system, the integrated ABR system can be considered accurate. The ABR system's accuracy was evaluated using two tests:

1)FPT-05-Travel-Time Accuracy Test: Travel times calculated by the ABR system for the two routes had to be accurate to generate reliable and precise diversion messages since the major requirement for the generation of a diversion message was the presence of significant traveltime difference between the GSP and U.S. 9. The ground truth data for this test were collected using Rutgers test vehicles traveling on the two alternate routes.

2)FTP-01-Bus Routing Test: The main purpose of this test was to evaluate if the ABR system bus routing algorithm generated reliable and accurate routing advisories based on the travel-time estimations of the $A B R$ system. The ABR bus routing algorithm generated diversion messages and sent them to buses traveling across the project section only if:

- the difference between the system estimated trip time at the GSP and U.S. 9 was larger than a preestablished threshold value (set at four minutes),

- the trip time at the GSP was greater than a preestablished threshold value (set at five minutes), or 
- the diversion message was not overridden by the system operators.

The travel-time accuracy test (FPT-05) was based on the testing of the differences in travel times estimated by the ABR system and actual travel times observed by the Rutgers test vehicles. These travel times were route travel times at any given time "t" and ABR system used point travel-time measurements in combination with probe vehicle (bus) travel times to estimate travel times on both routes. Thus, the Rutgers team decided to use instrumented test vehicles to measure actual travel times on both routes and compare these measurements with $\mathrm{ABR}$ system route travel-time estimates.

These ground truth route travel-time data were collected by the Rutgers evaluation team using two instrumented vehicles to conduct synchronized, parallel runs on the GSP and U.S. 9 from 6:30 A.M. to 9:00 A.M. to analyze the travel-time estimation process. Travel-time data from the Rutgers vehicle was compared with the ABR system travel-time estimates. Trip times were calculated based on these equations.

$T T(G S P)=$ Time $($ ICT/GSP)-Time $($ RAR/GSP $)$

$T T$ (US9) $=$ Time(ICT/US9) - Time(RAR/US9)

where:

TT (GSP) $=$ travel time for the Rutgers vehicle traveling on the GSP.

TT (US9) = travel time for the Rutgers vehicle traveling on U.S. 9.

Time $(\mathrm{ICT} /$ route $)=$ time the Rutgers vehicle crossed the radar placed at NJT-11. The /route indicates which route was taken (GSP or U.S. 9).

Time $(\mathrm{RAR} /$ route $)=$ time the Rutgers vehicle crossed the radar placed before the Raritan Toll Plaza. The /route indicates which route was taken (GSP or U.S. 9).

The system estimates travel times every four minutes. Each estimate is valid until another travel-time estimation is computed by the system.

Table 6 summarizes both route travel times estimated by the GSP ABR system and measured by the Rutgers test vehicles. The system's general trend was to underestimate the travel times with a reasonable order of magnitude. 
The difference in travel times given by the system and by actual travel times can be reasonably modeled as a normal distribution. Additionally, the system showed more variability when comparing estimated and actual travel times at U.S. 9 than the GSP, according to analysis of the standard deviation of the travel-time differences.

\begin{tabular}{|cccc|}
\hline \multicolumn{5}{|c|}{ Table 6} \\
\multicolumn{2}{|c|}{ Summary of Travel-Time Differences (in seconds) (November 25, 1997) } \\
\hline Route & \multirow{2}{*}{ Mean Rutgers Travel Time } & $\begin{array}{c}\text { Mean System Travel Time } \\
\text { (seconds) }\end{array}$ & $\begin{array}{c}\text { Differences } \\
\text { (seconds) }\end{array}$ \\
\hline GSP & & 382 & 123 \\
U.S.9 & 505 & 337 & 179 \\
\hline
\end{tabular}

\section{Evaluation of In-Vehicle Operations}

The NJT buses that were part of the ABR project were equipped with onboard transponders and annunciators. These devices provided direct communication to the equipped buses to transmit route guidance messages. Similar devices have been used in other ITS projects, and the proper functionality of these onboard devices are crucial to ensure the complete link between the central computer system (responsible for the decision-making process) and the bus operator (agent responsible for the implementation of the diversion instructions).

The evaluation of in-vehicle operations encompasses the analysis of message quality sent to participating buses. These issues were investigated for a complete evaluation of the quality messages:

- length and time of message sending,

- clarity of messages,

- location the message is transmitted, and

- external facts affecting the messages quality.

The length and time of message sending was analyzed through the use of a customer satisfaction survey. According to the sample of bus operators that filled out the questionnaire, the length and time of message sending did not achieve excellent marks, therefore leaving room for further improvement.

The audio message test (FTP-02) was performed by activating the transponders on the instrumented vehicles during test runs to verify that mes- 
sages could be received at normal highway speeds at the Raritan Toll Plaza and NJT-11. When transponder tests were conducted using Rutgers test vehicles, the initial message was heard at the proper location, right before the Raritan Toll Plaza. The message was also heard clearly under a variety of weather conditions, such as clear and rainy. The intensity of the volume and clarity of the message were acceptable during the test vehicle runs.

According to audio message testing results conducted by the Rutgers evaluation team, the length, time, and road position of messages sent were found to be adequate for the project purposes. However, the results of the questionnaire from the bus operators indicated that the system requires further improvement. This difference is due to the fact that bus operators that were new or not familiar with the GSP ABR study had difficulty understanding the diversion messages. They were sometimes also surprised with the message, sent just before the Raritan Toll Plaza. However, the simple capability of repeating the messages by pressing a button on the transponders could have solved this problem without any major changes to the system.

\section{Evaluation of the Integrated ABR System Performance}

The GSP ABR system consists of several components that perform specific functions. The evaluation of the integrated system was performed during the official testing period to test the system's:

- capability to produce effective diversion messages that reduce NJT bus travel times;

- ability to be understood and interact with its users, namely, bus drivers and operators; and

- capability of creating a positive perception among users regarding the system outputs, such as quality of messages and number of useful diversion messages issued.

Two major testing activities were conducted during morning rush hours at a maximum level of system requirements:

1) SW-01-Bus Travel-Time Reduction Test. System output was used to conduct the "bus travel-time" reduction test. 
2) SW-03-Consumer Satisfaction Test. Surveying was chosen as the major tool to conduct the consumer satisfaction test. Both bus drivers and system operators were surveyed to understand their perception of the ABR technology. The surveys were also useful in identifying areas of improvement for the system.

\section{Bus Travel-Time Reduction Test (SW-01)}

This test was performed by analyzing the system's output of diversion messages. During the testing days, system diversion messages, advising the use of the alternate route (U.S. 9), were issued. The occurrence and the time they affected a tagged vehicle traveling in the system were collected and the results were summarized and analyzed.

A summary of diversion messages compiled during the testing period showed that no diversion message, except one on December 11, 1997, lasted more than 15 minutes (Ozbay et al. 1998). The real length of the diversion message is a multiple of 4 minutes because the system issues new diversion messages at this rate. The effective length of a diversion message is equal to or smaller than a multiple of 4 minutes and may be used as a measurement of system performance because it also counts the rate that buses enter the system. This rate is proportional to the number of participating buses in the project. Table 7 gives a summary of diversion messages generated by the system during the testing period. The relatively low number of diversion messages during the testing period makes it difficult to draw conclusions regarding this issue. Given the traffic and network conditions of the ABR system, it was found that the probability of a diversion was very low (Table 8). This result limited the usefulness of the GSP ABR system in terms of understanding the effects of real-time bus routing because there were not too many cases where diversion of NJT buses from the GSP to U.S. 9 was warranted.

Table 7 shows that the most important factor for the system to be effective is its capability of transmitting the diversion message to the buses at the right time and at the right place. For example, although there were nine buses traveling during the time period when the diversion message was broadcast by the system, only three buses received the message. This might be partly due to 
the fact that they were not at the right location at the right time. Thus, it is extremely important to choose the best locations and most effective timing for disseminating diversion messages to the buses.

\section{Consumer Satisfaction Test (SW-03)}

This test was designed to measure the success of implementing a new technology that basically depends on user acceptance. Therefore, customer satisfaction is an important aspect of the integrated system evaluation. The main users of the ABR system are the NJT bus operators and the system operators who monitor the system. Customer satisfaction surveys were conducted in two parts: one set of surveys was designed for bus operators and the other for system operators.

\section{Summary of Survey Results Conducted among Bus Operators}

Twenty-one NJT bus operators were surveyed and interviewed on December 11, 1997, the final week of official testing at the Howell garage. The survey was designed to query bus operators in three areas: message transmission, routing information, and equipment.

The analysis of the surveys revealed several important points:

- All of the operators were familiar with the alternate route (U.S. 9).

- Sixty-three percent of the operators did not find the diversion messages clear, while 47 percent of the operators thought the sound quality could be improved by increasing the volume. Sixty-eight percent of the drivers replayed the diversion message.

\begin{tabular}{|c|c|c|c|}
\hline \multicolumn{3}{|c|}{ Summary of Diversion Messages } \\
\hline Date & $\begin{array}{c}\text { No. of Tagged } \\
\text { Vehicles that } \\
\text { Diverted }\end{array}$ & $\begin{array}{c}\text { No. of Tagged Vehicles in the } \\
\text { System during the Diversion } \\
\text { Message }\end{array}$ & $\begin{array}{c}\text { No. of Tagged Vehicles that the } \\
\text { Message was Transmitted to at Raritan } \\
\text { Toll Plaza }\end{array}$ \\
\hline $11 / 17 / 97$ & 2 & 9 & 3 \\
\hline $11 / 18 / 97$ & 0 & 1 & 0 \\
\hline $11 / 20 / 97$ & 3 & 11 & 5 \\
\hline $11 / 25 / 97$ & 1 & 6 & 6 \\
\hline $12 / 11 / 97$ & 0 & 5 & 1 \\
\hline $12 / 12 / 97$ & 0 & 4 & 0 \\
\hline $12 / 15 / 97$ & 1 & 3 & 1 \\
\hline $12 / 16 / 97$ & 0 & 2 & 0 \\
\hline $12 / 17 / 97$ & 1 & 2 & 1 \\
\hline
\end{tabular}




\section{Table 8}

Summary of Travel-Time Differences on GSP and U.S. 9 (in seconds) (Travel-Time Difference $=$ TravelTime_GSP- TravelTime_US 9)

\begin{tabular}{|c|c|c|c|}
\hline Date & $\begin{array}{c}\text { No. of Tagged } \\
\text { vehicles that } \\
\text { Diverted }\end{array}$ & $\begin{array}{c}\text { No. of the Tagged Vehicles } \\
\text { in the System during the } \\
\text { Diversion Message }\end{array}$ & $\begin{array}{c}\text { No. of Tagged Vehicles that the } \\
\text { Messages was transmitted to at } \\
\text { Raritan Toll Plaza }\end{array}$ \\
\hline $11 / 17 / 97$ & 2 & 9 & 3 \\
\hline $11 / 18 / 97$ & 0 & 1 & 0 \\
\hline $11 / 20 / 97$ & 3 & 11 & 5 \\
\hline $11 / 25 / 97$ & 1 & 6 & 6 \\
\hline $12 / 11 / 97$ & 0 & 5 & 1 \\
\hline $12 / 12 / 97$ & 0 & 4 & 0 \\
\hline $12 / 15 / 97$ & 1 & 3 & 1 \\
\hline $12 / 16 / 97$ & 0 & 2 & 0 \\
\hline $12 / 17 / 97$ & 1 & 2 & 1 \\
\hline
\end{tabular}

- Sixty-seven percent of the drivers were optimistic that the ABR system would improve travel time, while 47 percent believed that the alternate route provided an advantage after the diversion instruction.

- Eighty percent of the drivers thought the diversion message was accurate.

- Sixty percent of the bus drivers agreed that the ABR system saves travel time.

- Twenty-five percent of the drivers diverted to U.S. 9 when the diversion message instructed the operators to stay on the GSP.

- Eighty-five percent of the operators agreed that the equipment was functioning effectively and installed correctly.

\section{Summary of Survey Results Conducted among System Operators}

The system operators of the ABR project who monitor the GSP ABR system from the traffic operation center in Maplewood were also surveyed. The operator survey form consisted of three main sections: routing information, software management, and equipment. The conclusions of the survey, conducted among three system operators, are summarized below.

Routing Information. All three operators believed the system's diversion decisions were almost correct. Two operators stated that they overrode the sys- 
tem's diversion message once because they felt the diversion was not warranted. They also agreed that the alternate route did not save any time at all. The operators unanimously agreed that the system could have potentially provided useful information if the alternate route had been different. They also all agreed that the ABR system can be enhanced by improving the performance of the existing camera and adding new cameras.

Software Management. The software operation training and information provided by the software developers were rated as adequate. The volume, speed, and occupancy information displayed by the software were also found satisfactory by the system operators.

Equipment. There was a difference of opinion among the three operators regarding the functioning of the surveillance camera. One operator rated most of the camera functions as perfect while another operator rated them as barely adequate or poor. The third operator rated all camera functions as average or adequate.

\section{Conclusions}

Based on the results of the evaluation, two important conclusions specific to this FOT are evident:

1) Similarity of travel times on both routes (Table 8). Even if one route gets congested, the other route gets quickly congested, too, due to the drivers switching to the alternate route. This, in turn, limits the usefulness of the ABR system by eliminating the possibility of directing NJT buses to the uncongested route. During morning travel-time data collection, the locations on the GSP and U.S. 9 that were affected during the rush hour were found before the Raritan Toll Plaza, Driscoll Bridge, and NJT-11 tollbooth.

2) The ABR system used tag data upon the completion of a trip. Thus, diversion decisions were based on this completed run, using basically the system conditions that existed 5 to 10 minutes before the bus entered the system. Therefore, when the next bus received a route diversion message, this trip-time information may not have reflected the "actual" realtime system conditions. This problem can be remedied by modifying the 
$\mathrm{ABR}$ system to receive bus travel times at intermediate locations and not just at the end of the trip.

\section{Lessons Learned}

Several more general conclusions based on the system-specific conclusions and evaluation results can be used in the design of future successful APTS FOTs.

- Network and traffic conditions play an important role in the successful testing and evaluation of any ITS technology. Therefore, site selection for any FOT is of great importance. In this study, the selected network was too small and thus the travel-time differences between the two alternate routes were not statistically significant. This limited the usefulness of the FOT in terms of assessing the effectiveness of the system. This could have been easily identified as a potential problem if a simulation study had been performed prior to the initiation of the actual field study.

- Hardware and equipment problems are almost always site specific. The accuracy of sensors depends heavily on the appropriate installation and maintenance of the equipment. For example, RTMS that are widely used at other places had several problems in this FOT, mainly due to installation and site-specific problems.

- Hardware was the source of most of the major problems in this project. Due to the equipment and possibly some algorithmic estimation problems for the testing days, travel-time estimations of the ABR system were different than the ground truth travel times collected by the evaluation team. This type of equipment problem can seriously reduce the effectiveness of a real-time system. Operating conditions also play an important role in the successful implementation of even proven technologies such as annunciators used in this project. Messages were clear when tested by the test vehicles. However, 63 percent of the operators did not find the diversion message clear, while 47 percent of the operators thought the sound quality could be improved by increasing the volume. Sixty-eight percent of the drivers replayed the diversion message. 
- System users are usually open to new ITS technologies. However, the actual performance of the system plays an important role in ensuring the acceptance of the system by its users in the long term. Another important point is the need for involving system users before and during the implementation of any new ITS system and making sure that the system effectively responds to the needs of the actual users.

- The project team decided not to pursue the second phase of the project, which involved instrumentation of 350 NJT buses. The limitation of the test network in terms of travel-time differences between the two routes played an important role in this decision.

\section{Acknowledgments}

This project has been partially funded by a grant from the New Jersey Highway Authority. The contents of this article reflect the views of the authors who are fully responsible for the facts, accuracy of the data, and conclusions presented in the article and do not necessarily reflect those of NJHA and other organizations involved in this study.

\section{References}

Gardener-Rowe Systems. 1995. Single Point Diversion Strategy for the New Jersey Garden State Parkway.

Hughes Electronics. 1995. Alternate Bus Routing Project Functional Specification, Garden State Parkway Pilot System. Hughes Electronics.

Ozbay, K., M. Jafari, D. Feldhaus, T. Karunaratne, and T. P. Williams. 1998.

Evaluation of Garden State Alternate Bus Routing Project. Final Report.

Piscataway, NJ: Rutgers Intelligent Transportation Systems (RITS) laboratory, Rutgers University.

Ozbay, K., and P. Kachroo. 1999. Incident management for Intelligent Transportation Systems. Norwood, MA: Artech House Publishers.

U.S. Department of Transportation, Federal Highway Administration. 1996. Alternate Bus Routing: New Jersey Parkway. Project Overview Presentation, Washington DC. 
U.S. Department of Transportation. 1995. National ITS plan. First Edition, Volumes I and II. Washington, DC: U.S. Department of Transportation, ITS America.

\section{About the Authors}

KAAN OZBAY (kaan@rci.rutgers.edu) is an assistant professor at Rutgers University Department of Civil and Environmental Engineering.

Diogenes Feldhaus (dfeldhau@embraco.com.br) was a graduate student at Rutgers University Department of Industrial Engineering.

Tilanka Karunaratne was a graduate student at Rutgers University Department of Civil and Environmental Engineering.

MoHSEN JAFARI (jafari@rci.rutgers.edu) is an associate professor at Rutgers University Department of Industrial Engineering.

TREFOR Williams (tpw@rci.rutgers.edu) is an associate professor at Rutgers University Department of Civil and Environmental Engineering. 